Research in Social Sciences and Technology (RESSAT) Volume 5 Issue 2, 2020
Tarman, B. (2020). Editorial: Reflecting in the shade of pandemic.

\title{
Editorial: Reflecting in the Shade of Pandemic
}

\author{
Bulent Tarman \\ Editor-in-Chief, RESSAT \\ btarman@ressat.org
}

DOI: $10.46303 /$ ressat.05.02.ed

Tarman, B. (2020). Editorial: Reflecting in the Shade of Pandemic. Research in Social Sciences and Technology, 5(2), I-IV. doi.org/10.46303/ressat.05.02.ed

I hope this editorial note finds you well and healthy, especially amid the uncertainty due to COVID-19. We are concerned about our children, families, neighbors, colleagues, and ourselves. We are contending with daily reports of death presented as the centerpiece headline news while we are dealing with grief and uncertainty. The impact of this current pandemic on society, in general, is increasingly visible, and we find ourselves in a permanent state of transformation due to the dizzying proliferation of technologies. This pandemic expedites the vital role of Information and Communication Technology (ICT) that drives the modern world in education as well as in all other areas. On the other hand, as schools and higher education institutions rapidly move their learning, teaching, and assessment online in response to the worldwide pandemic, academics feel improvised, inefficiently supported, and deeply fearful (Watermeyer et al., 2020). ${ }^{1}$

I hope all of you are doing your best at adapting and finding the way of your teaching styles and courses, grace, and humanity that still exist despite the difficulties we face during this pandemic. I feel the joy of being home with my family and having more hours to contemplate the existing issues humanity faces and how it will end up and what changes it will bring to our social, cultural, and professional lives. We do not know what new panic tomorrow will bring; however, it seems doubtless that "this pandemic will teach people many lessons"

\footnotetext{
1 This is based on the findings of a recent study: "In total, an excess of 1400 responses were generated from academics working in higher education institutions across 40 country contexts. These are voices of experience representing all the major disciplinary areas and career stages from which transpire the enormous challenges that this pandemic presents to academic lives and careers... The physical closure of university campuses by the Covid19 pandemic has almost overnight changed 'how we do what we do' as academics, and the nature of our daily routines" (Watermeyer et al., 2020).
} 
(Rapoport, 2020). Some people have already started criticizing (including self-critics) the existing systems in almost all areas, asking whether this happens because of the injustice and unfairness occurring everywhere at every level (individual, local, national, and global) since the majority stay silent and do not show any reaction to these injustices. No matter what/who the cause of this pandemic is and how it ends, we all understand the fact that we were not aware enough until we lost our blessings. I hope that we as people remember the lessons we are learning now about responsibility, citizenship, and what really matters in life.

Keeping our scholarly activities in mind, "There is nothing like a crisis to make you realize what is important and this could not be truer than in the world of scholarly communication" (Gadd, 2020). The real purpose of scholarly communication is not to allocate credit for career advancement but to communicate with each other, to share insights for the benefit of humanity.

Presented in this edition are eight articles that discuss the points of view of various areas of education from several different parts of the world. It is our intention to contribute to the analysis and discussion of empirical research and theoretical aspects linked to the development of technologies in formal and informal learning processes showing significant approaches in a Global World.

The first article, written by Alvyra Galkiene and Giedre Puskoriene, is Development of Adaptation Tools for Pupils on the Autism Spectrum in Microsystems. In their research, the authors investigate the possibilities for the development of adaptation tools for pupils on the autism spectrum (AS) studying in the first and second forms within their microsystems. The result of this research reveals that the development of adaptation tools in children on the AS is determined by a mesosystem that covers various combinations of microsystems, and the synergy between the factors of the microsystems creates conditions for a child's gradual transfer from one microsystem to another, perceiving the mechanisms of its functioning and adapting within them.

Raymond Chee-Yen Loh and Chin-Siang Ang are the authors of Unravelling Cooperative Learning in Higher Education: A Review of Research. The authors start by defining cooperative learning, discuss the elements inherent in this pedagogy, and outline the theoretical perspectives relating to cooperative learning $(\mathrm{CL})$. This review study concludes that $\mathrm{CL}$ is an 
effective teaching and learning approach in higher education. Findings appear to be consistent with the notion that $\mathrm{CL}$ helps to enhance academic, affective, and social development of students. The authors also emphasize the role of culture on determining how $\mathrm{CL}$ is valued in a particular cultural context.

In \#Education: The Potential Impact of Social Media and Hashtag Ideology on the Classroom, Ellen Watson analyzes scholarly works discussing the use of hashtags with K-12 students to answer this question: How can the hashtag inform the K-12 classroom? Findings of the study indicate four themes that could inform the alignment of K-12 classrooms with hashtag ideology: encouraging voice and user-generated content, the potential of self-organization, network hetero/homogeneity, and connecting to space without a common physical space.

Marta Camarero-Figuerola, Jorge-Manuel Dueñas, and Ana-Inés Renta-Davids are the authors of The Relationship Between Family Involvement and Academic Variables: A Systematic Review. This research reveals that family participation is a variable that protects against academic failure and that this relationship is stronger in vulnerable populations and ethnic minorities.

In The Impact of Teacher-Initiated Activities on Identifying and Verbalizing Ways of Metacognitive Monitoring and Control in Six-Year-Old Children, Ona Monkevičienè, Jelena Vildžiūnienè, and Galina Valinčienè explore the impact of teacher-initiated activities on six-yearold children's metacognitive monitoring and control abilities. The results of the research show that teacher-initiated activities stimulate and encourage children to find and apply more diverse ways of metacognitive monitoring and control.

Malliga K. Govindasamy and Ngu Moi Kwe are the authors of Scaffolding Problem Solving in Teaching and Learning the DPACE Model - A Design Thinking Approach. This research intends to validate the effectiveness of the DPACE model in facilitating pre-service teachers in planning and executing a solution for an identified instructional problem. The result of this research validates that the DPACE model is a powerful approach to thinking and problem solving, as the concepts are grounded in sound pedagogical theories.

In Comparing Pre-service Civic Education Teachers' TPACK Confidence Across Course Modes: Insights for Future Teacher Education Programs, Imam Fitri Rahmadi, Eti Hayati, and 
Aulia Nursyifa compare pre-service civic education teachers' TPACK confidence across three course modes of a pre-service teacher education program in Indonesia.

In the last article of this issue, Multidimensional Analysis of the Teaching Process of the Critical Thinking Skills, Seyat Polat evaluates critical thinking skills in a multidimensional way by focusing on the level of teachers' critical thinking skills. The author analyzes how teachers conceptualize critical thinking, their practices of critical thinking in the classroom, and if the critical thinking is referred enough in the curriculum by using a mixed-method research design.

We are honored to present this issue, and we thank the authors and reviewers for their contribution to RESSAT. We hope you will enjoy and be challenged by the articles in this issue, and we look forward to seeing your contribution to the development of RESSAT in the future.

\section{References}

Gadd, E. (2020, April 20). The purpose of publications in a pandemic and beyond. Wonkhe. Retrieved from https://wonkhe.com/blogs/the-purpose-of-publications-in-a-pandemic-and-beyond/

Rapoport, A. (2020). From the editor: Global pandemic: A painful lesson for social studies educators. Journal of International Social Studies, 10(1), 1-2.

Watermeyer, R., Crick, T., Knight, C., \& Goodall, J. (2020, April 9). Forced shift to online teaching in coronavirus pandemic unleashes educators' deepest job fears. Nature Index. Retrieved from https://www.natureindex.com/news-blog/forced-shift-to-online-teaching-incoronavirus-pandemic-unleashes-educators-deepest-job-fears- 